Mini Review

\section{Climate and garbage}

\section{Khalidullin Oleg*}

Almaty, 050051, Kazakhstan

Humanity has destroyed $70 \%$ of the land by arable land, reservoirs, asphalt, concrete, garbage and ore landfills.

Each of us sends 400-500 kg of garbage to the landfill per year. If from the garbage that the inhabitants of Russia throw out in a year, they built a tower with an area of one meter by one meter, then it would be possible to get to the Moon through it: https://greenpeace.ru/wp-content/uploads/2019/10/ report-RUSSIA -GARBAGE.pdf

The area of the world's landfill on land is the size of Mexico, and it is growing.

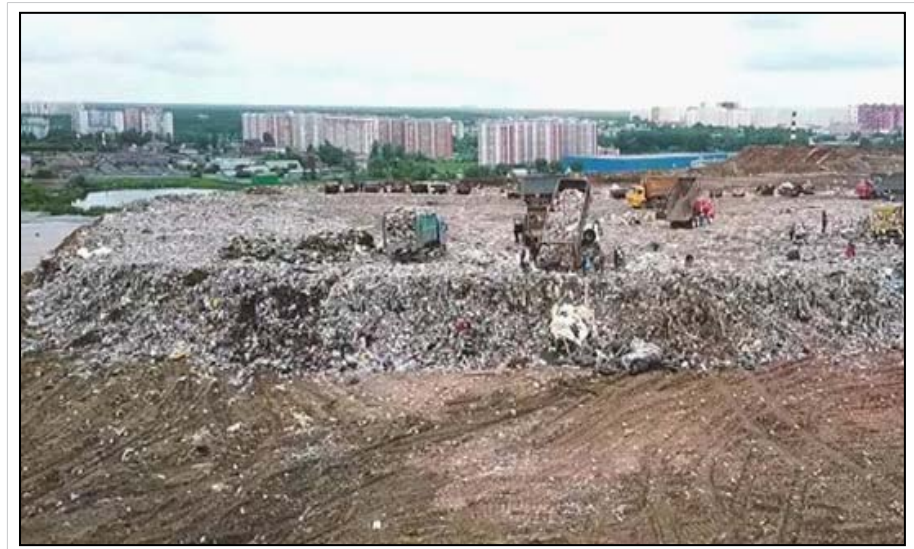

One of the major reasons for this is the destruction of soil under landfills. There, 20 tons of underground living creatures perish on each hectare: https://smoldacha.ru/ osnovy_prirodnogo_zemledeliya.html. All these living creatures supply terrestrial biota with their products, which also successfully disappears. http://kartinamira.info/ science/429-ischeznovenie-vidov: Nowadays, every year one animal species disappears without a trace on the planet, and every day - one plant species with a close prospect of hourly extinction. By the way, there are four times less plant species that are disappearing at such a catastrophic rate than animals, while plants form the basis of all food pyramids, and their diversity is the basis of pharmaceuticals. The extinction rate of living species in the modern era is 1000 times higher than in the era of extinction of the dinosaurs, which we consider mysterious and catastrophic. And this takes place in conditions when, due to anthropogenic impact on nature, natural speciation has practically ceased.

\author{
More Information \\ *Address for Correspondence: \\ Khalidullin Oleg, Almaty, 050051, Kazakhstan \\ Tel: +77770550099; Email: 7115215@mail.ru \\ Submitted: December 10, 2020 \\ Approved: January 20, 2021 \\ Published: January 21, 2021
}

How to cite this article: Oleg K. Climate and garbage. Ann Civil Environ Eng. 2021; 5: 001-002.

DOI: 10.29328/journal.acee.1001027

Copyright: (ৎ) 2021 Oleg K. This is an open access article distributed under the Creative Commons Attribution License, which permits unrestricted use, distribution, and reproduction in any medium, provided the original work is properly cited.

Check for updates

OPEN ACCESS

Destruction of biota is dangerous for the planet because natural evaporation decreases and evaporation of waters that do not perform their functions on earth increases. The area covered with debris blocks the movement of rainwater to the soil, wets the upper layers of paper, plastic, metal, glass, does not find its consumers and returns to the atmosphere without fulfilling its natural functions. Such vapors create a different water cycle that affects the climate. More details: https:// msdpublications.com/uploads/article/RIJEES-01-1003.pdf

The main types of waste in terms of volume are polyethylene and plastic in landfills. Separate waste collection and recycling is known and widely used in developed countries. It is enough to apply everything known to eliminate all waste landfills

Such achievements have been fully implemented in the Scandinavian countries and Japan. A high culture of waste management leads to the centralization of enterprises for the disposal and treatment of various waste in special enterprises on a large scale. Plastics and polyethylene are recycled into pellets and reused for casting new products.

For this, powerful enterprises are being built for the cleaning and processing of all types of waste.

In less developed countries, it is necessary to look for more suitable, budgetary, rational ways of disposing of waste.

One of the interesting possibilities is the disposal of garbage using it in useful items without deep cleaning and processing. It is known that plastic dishes do not decompose for hundreds of years. And what if you use this factor for good. You can fill the cavity of a plastic or thin-walled pipe 
with dry, non-rotting debris, tamp and seal the ends, then its strength will increase many times over. Low posts can be used as supports for fences. Larger diameters can become piles. Mixing the debris with an appropriate fixing agent such as cement or foam and placing the tensioned reinforcement will enable it to be used as a support for power lines. Filling smalldiameter pipes will allow the manufacture of furniture legs, railings, and many other products in everyday life, especially in summer cottage construction. Large diameters cut into discs can become wheels, tabletops, seats. Filling the cavity with debris between two pipes of different diameters inserted into one another will give a heat-insulating pipeline. Filling and sealing can be mechanical, specially prepared devices.

Strategically, protecting the environment requires reducing or eliminating the production of any type of plastic. But a different look at waste material can radically change the attitude towards it. It is possible to create new raw materials for direct use in construction and everyday life, use it in the production of other items. The well-known phrase "waste to income" is becoming quite real. Compression with low heat in special shapes will allow the creation of sheet material. For example, plastic, newspapers and cardboard. When stacked in piles, interspersed with glue or heat, you can get a durable and waterproof sheet material, such as countertops and window sills. All other types of waste, except food waste, can be compressed into such pipes or other closed sealed volumes.

Pipes of large diameters from one meter to several can accommodate all dry waste without sorting. After the ends are sealed, the remaining space is filled with expanding material such as foam and provides support for any construction on land and under water, for example, to increase islands, the construction of quays and a host of other structures. And if you leave there space for changing the volume of air inside, then you can achieve a given buoyancy and create floating islands out of them.

It is possible to manufacture special hollow bricks - blocks. In the construction of walls, these containers after use can be filled with sand, sawdust, crumpled or crushed plastic bags, crushed non-rotting waste of all other types of garbage, and laid out the walls from them. Walls are load-bearing, but frame construction is also known with filling the inter-column space with lightly loaded and non-bearing walls.

Thus, it becomes possible to use all waste and eliminate landfills without expensive recycling plants. Then all household waste can be sorted into 3 types. Food grade, combustible and everything else.

There is no need for powerful expensive technologies and waste processing plants. Everything will go into such containers from plastic bags to refrigerators and even cars.

Reclamation and complete elimination of waste dumps leads to a decrease in artificial and an increase in organic evaporation - a fairly significant factor in reducing the impact on the water cycle and climate change.

To implement this method, it is enough to create small companies working directly near the primary waste collection points. 